\title{
Antiarthritic effect of aqueous and ethanolic leaf extracts of Pistia stratiotes in adjuvant-induced arthritis in Sprague-Dawley rats
}

This article was published in the following Dove Press journal:

Journal of Experimental Pharmacology

20 March 2012

Number of times this article has been viewed

\author{
Samuel Kyei ${ }^{1}$ \\ George A Koffuor \\ Johnson N Boampong ${ }^{2}$ \\ 'Department of Pharmacology, \\ Faculty of Pharmacy and \\ Pharmaceutical Sciences, College \\ of Health Sciences, Kwame Nkrumah \\ University of Science and Technology, \\ Kumasi, Ghana; ${ }^{2}$ Department of \\ Human Biology, School of Biological \\ Sciences, University of Cape Coast, \\ Cape Coast, Ghana
}

Background: Pistia stratiotes has been used effectively to treat a number of inflammatory conditions. This study aims to determine the antiarthritic effect of aqueous and ethanolic leaf extracts of $P$. stratiotes.

Methods: Arthritis was induced in Sprague-Dawley rats, paw swelling was measured, and arthritis indices were estimated in rats treated with aqueous and ethanolic leaf extracts of P. stratiotes (AQ PSE and ET PSE, respectively), methotrexate, diclofenac, dexamethasone, and normal saline-treated rats. Radiologic imaging, hematological assessment of red and white blood cells, C-reactive protein and erythrocyte sedimentation rate, as well as histopathological studies were also done. The data were analyzed using GraphPad Prism 5.

Results: The 30,100 , and $300 \mathrm{mg} / \mathrm{kg}$ doses of AQ PSE and the 30 and $100 \mathrm{mg} / \mathrm{kg}$ doses of ET PSE caused a significant $(P \leq 0.05-0.001)$ reduction in ipsilateral paw swelling, similar to the effects of methotrexate, dexamethasone, and diclofenac. Only the $30 \mathrm{mg} / \mathrm{kg}$ dose of AQ PSE caused a significant $(P \leq 0.01)$ reduction in contralateral paw swelling. Arthritic indices reduced significantly $(P \leq 0.05-0.001)$ at all drug doses, except for the 100 and $300 \mathrm{mg} / \mathrm{kg}$ doses of ET PSE. White blood cell levels decreased significantly $(P \leq 0.05-0.01)$ in arthritic rats treated with the $30 \mathrm{mg} / \mathrm{kg}$ dose of AQ PSE and those treated with methotrexate. Erythrocyte sedimentation rate and C-reactive protein levels were significantly $(P \leq 0.01-0.001)$ lower in all the treatment groups except for the rats treated with AQ PSE $300 \mathrm{mg} / \mathrm{kg}$ and ET PSE 100 and $300 \mathrm{mg} / \mathrm{kg}$ doses. The arthritic animals treated with $30 \mathrm{mg} / \mathrm{kg}$ of the aqueous extract showed no inflammatory changes in the ipsilateral paw, while the contralateral paw showed only foci of mild chronic inflammatory changes, as seen with the reference drug treatment in histopathological studies.

Conclusion: This study establishes that aqueous and ethanolic extracts of $P$. stratiotes have antiarthritic activity in Sprague-Dawley rats with induced arthritis. The aqueous extract had better activity than the ethanolic extract.

Keywords: Pistia stratiotes, arthritic index, radiological index, C-reactive protein, ipsilateral paw, inflammation

\section{Introduction}

Inflammation is implicated in many diseases, and its consequences tend to be worse if resolution fails and inflammation progresses to a chronic stage. ${ }^{1}$ Although inflammation is a body defense mechanism, its role in the maintenance and aggravation of various disease conditions (such as rheumatoid arthritis) is of public health importance and makes it a subject of scientific interest and clinical concern. ${ }^{2}$
Correspondence: George A Koffuor Department of Pharmacology, Kwame Nkrumah University of Science and

Technology, Kumasi, Ghana

Tel +23327740 0312

Email gkoffuor@yahoo.com
C) 2012 Kyei et al, publisher and licensee Dove Medical Press Ltd. This is an Open Access article which permits unrestricted noncommercial use, provided the original work is properly cited. 
Arthritis, an autoimmune disorder, is a chronic inflammatory disease which manifests itself in multiple joints of the body. The inflammatory process primarily affects the lining of the joints (synovial membrane), but can also affect other organs. The inflamed synovium leads to erosions of the cartilage and bone, and sometimes to joint deformity. Pain, swelling, and redness are common joint manifestations. ${ }^{3}$

Arthritis causes disability, compromised quality of life, and premature mortality. ${ }^{4}$ It affects approximately $0.5 \%-1.0 \%$ of the global adult population, with an estimated annual incidence of 12.0-24.5 males and 23.9-54.0 females per $100,000.3,5,6$ The incidence is largely consistent racially and geographically, and the peak age of onset lies between the ages of 45 and 65 years. The economic cost of arthriticrelated diseases is estimated to consume about 3\% of gross domestic product in developed countries, and is somewhat lower in developing countries due to lower life expectancy. ${ }^{7,8}$ The present decade has therefore been declared the "Bone and Joint Decade" by the World Health Organization, ${ }^{9}$ in order to further our understanding of the impact of musculoskeletal diseases on society and individuals and to assist advancement on this front. It is against this background that we attempted to assess the antiarthritic effect of aqueous and ethanolic leaf extracts of Pistia stratiotes in a rodent adjuvant-induced arthritis model to ascertain its importance in the traditional management of inflammatory disorders. ${ }^{10,11}$

\section{Materials and methods}

\section{Plant collection}

P. stratiotes was collected from the Fosu Lagoon, Cape Coast, in the Central Region of Ghana $\left(5^{\circ} 7^{\prime} \mathrm{N}\right.$ and $\left.1^{\circ} 16^{\prime} \mathrm{W}\right)$ in December 2010. It was identified and authenticated by Mr GH Sam of the Department of Herbal Medicine, Kwame Nkrumah University of Science and Technology, where a voucher specimen bearing the number KNUST/ HM1/11/W002 has been deposited at the herbarium for future reference.

\section{Preparation of extracts}

The leaves of $P$. stratiotes were washed thoroughly with tap water and sun-dried. The dry leaves were milled into coarse powder by a hammer mill (Schutte Buffalo, New York, NY). In preparing the aqueous leaf extract of $P$. stratiotes, $700 \mathrm{~g}$ of the leaf powder was mixed with one liter of water. The mixture was maintained at $80^{\circ} \mathrm{C}$ (in a round-bottomed flask fitted with a reflux condenser) in a thermostatically controlled water bath for 24 hours and then filtered.
The filtrate was freeze-dried with a Hull freeze-dryer/ lyophilizer 140 SQ FT (model 140FS275C; Hull, Warminster, PA) into powder (yield 4.7\%) and stored at a temperature of $4^{\circ} \mathrm{C}$ in a refrigerator. This powder was reconstituted in normal saline to the desired concentration and labeled as the aqueous extract of $P$. stratiotes (AQ PSE) for dosing in this study. Similarly, $700 \mathrm{~g}$ of the leaf powder was soaked with one liter of $70 \%$ ethanol at room temperature $\left(27^{\circ} \mathrm{C}-29^{\circ} \mathrm{C}\right)$ for 72 hours and filtered. The filtrate obtained was freeze-dried into powder (yield 5.2\%). Quantities of this powder were reconstituted in normal saline at the desired concentrations to be referred to and used in this study as the ethanolic leaf extract of $P$. stratiotes (ET PSE).

\section{Drugs and chemicals}

Complete Freund's adjuvant (CFA) was a $5 \mathrm{mg} / \mathrm{mL}$ suspension of heat-killed Mycobacterium tuberculosis (strains C, DT and PN [mixed] obtained from the Ministry of Agriculture, Fisheries and Food, UK) triturated in paraffin oil (Ernest Chemist, Accra, Ghana) was used for the induction of arthritis. Diclofenac sodium (KRKA, Novo mesto, Slovenia), dexamethasone sodium (Anhui Medihel Co, Ltd, Hefei, Anhui, China), and methotrexate sodium (Dabur Pharma, New Delhi, India) were the reference anti-inflammatory agents in this study.

\section{Preparation of reference drugs}

The reference anti-inflammatory drugs were dissolved in normal saline for the study. The drugs were freshly prepared and administered in volumes not exceeding $10 \mathrm{~mL} / \mathrm{kg}$.

\section{Animals}

Male and female 6-8-week-old Sprague-Dawley rats (weight 180-200 g) purchased from the Centre for Scientific Research into Plant Medicine, Mampong-Akwapim, Ghana, were maintained in the Animal House of Department of Pharmacology, Kwame Nkrumah University of Science and Technology, Ghana. The animals were housed in polyacrylic cages $(34 \mathrm{~cm} \times 47 \mathrm{~cm} \times 18 \mathrm{~cm})$ with soft wood shavings as bedding, under ambient laboratory conditions (temperature $28^{\circ} \mathrm{C} \pm 2{ }^{\circ} \mathrm{C}$, relative humidity $60 \%-70 \%$, and a normal light-dark cycle). None of the females were pregnant. They were fed on a normal commercial pellet diet (GAFCO, Tema, Ghana) and had access to water ad libitum. All procedures and techniques used in these studies were in accordance with the National Institute of Health for the Care and Use of Laboratory Animals. ${ }^{12}$ Protocols for the study were approved by the departmental ethics committee. 


\section{Preliminary phytochemical screening}

Screening was performed on AQ PSE and ET PSE to ascertain the presence of phytochemicals using standard procedures described by Wagner and Bladt,,${ }^{13}$ Glasl, ${ }^{14}$ Harborne,,${ }^{15}$ and Kujur et al. ${ }^{16}$

\section{Induction of arthritis}

Arthritis was induced as previously described by Pearson, ${ }^{17}$ with slight modification. In this process, the initial hind paw volumes (both left and right) of the experimental animals were measured by water displacement plethysmography. ${ }^{18}$ The right hind paw of each animal was then injected with $0.1 \mathrm{~mL}$ of CFA. The paw volumes for both the injected paw (ipsilateral) and the noninjected paw (contralateral) were measured on day 1 after injection into the paw, and every other day. Unilateral inflammatory edema of the ipsilateral paw peaking at around days 4-6 was indicative of successful induction of adjuvant arthritis.

\section{Experimental procedure}

Nine days after adjuvant-induced arthritis, the animals were put into ten groups (A-J) of five and were randomized to treatment with either 30,100 , or $300 \mathrm{mg} / \mathrm{kg}$ of AQ PSE or ET PSE (orally daily), $0.3 \mathrm{mg} / \mathrm{kg}$ methotrexate (intraperitoneally every 4 days), $0.43 \mathrm{mg} / \mathrm{kg}$ diclofenac (intraperitoneally daily), $1 \mathrm{mg} / \mathrm{kg}$ dexamethasone (intraperitoneally, every other day), or $1 \mathrm{~mL} / \mathrm{kg}$ normal saline (orally daily) over the experimental period. A nonarthritic control group consisting of five animals in which incomplete arthritis was induced by intraplantar injection of $0.1 \mathrm{~mL}$ of sterile paraffin oil (incomplete Freund's adjuvant, [IFA]) and a normal control group in which there was no induction of arthritis were also studied. The effect of the reference and test drugs on the edema component of arthritis was quantified by measuring the difference in paw volume prior to induction of arthritis (day 0 ) and that at the various time points of assessment up to day 27. The arthritic index for the ipsilateral and contralateral paw volumes was individually calculated and expressed as a percentage change with respect to values at day 0 , and then averaged for each treatment group.

Initial body weights of the rats were recorded at day 0 and on day 28 . On day 28 , the experimental animals were sent to the radiology unit of the Kwame Nkrumah University of Science and Technology Hospital where they were anesthetized with ketamine hydrochloride for X-ray imaging using a conventional X-ray machine (Philips, Eindhoven, The Netherlands) and industrial X-ray film (Fuji Photo Film, Tokyo, Japan). The X-ray apparatus operated at a $52 \mathrm{kV}$ peak and 10 seconds of exposure with a $45 \mathrm{~cm}$ tube-to-film distance for lateral projections.

The rats were sacrificed and blood samples were collected into MediPlus K3 ethylenediamine tetra-acetic acid tubes (Sunphoria Co, Ltd, Taipei, Taiwan) for hematological analysis using the KX-21 N automated hematology analyzer (Sysmex Corporation, Chuo-ku, Kobe, Japan) and into trisodium citrate erythrocyte sedimentation rate tubes (Chengdu Rich Science Industry Co, Ltd, Sichuan, China) for estimation of erythrocyte sedimentation rate using the Westergren method..$^{19}$ Blood was also collected into glass tubes and centrifuged (temperature $25^{\circ} \mathrm{C}$, speed $4000 \mathrm{~g}$ ) for 5 minutes using a Mikro 220R (Hettich Zentrifuge, Tuttlingen, Germany) machine to obtain the plasma, which was used to estimate C-reactive protein levels using an enzyme-linked immunosorbent assay kit (Fortress Diagnostic Ltd, Antrim, Northern Ireland).

The right and left hind paws of the animals were amputated and fixed in $4 \%$ phosphate-buffered paraformaldehyde, decalcified with $1 \%$ ethylenediamine tetra-acetic acid, and embedded in paraffin. Sections were stained with hematoxylin and eosin, ${ }^{20,21}$ and fixed on glass slides for microscopic examination at the Pathology Department of the Komfo Anokye Teaching Hospital. Data obtained for the arthritic and radiological indices as well as histopathological, hematological, and physical profiles were analyzed.

\section{Arthritic index}

Photographs of the arthritic rats were taken on day 28 with a camcorder (Everio ${ }^{\mathrm{TM}}$ model GZ-MG1300; JVC, Tokyo, Japan). Inflammation in each paw was graded blindly by the same person for all rats on day 28 according to the extent of erythema and edema of the periarticular tissues, using a scale of 0-4 (Table 1). The arthritis score for each rat on day 0 was determined to be 0 . The scores for each paw were then added to get the total arthritis score (maximum possible score 16 per animal), and designated as the arthritic index.

\section{Radiological index}

Using the radiographs, the severity of bone and joint destruction was scored blindly by the same person for each hind

Table I Grading scale for arthritic index 22,23

\begin{tabular}{ll}
\hline Score & Description \\
\hline 0 & No inflammation \\
1 & Unequivocal inflammation of one joint of the paw \\
2 & Unequivocal inflammation of at least two joints of the paw \\
& or moderate inflammation of one joint \\
4 & Severe inflammation of one or more joints \\
\hline
\end{tabular}


limb according to the method described by Hoffmann et al. ${ }^{24}$ Briefly, radiographic scoring was performed by assessing soft tissue swelling, periosteal new bone formation, joint space narrowing, periarticular osteoporosis, and bone destruction on a scale of 0 (normal) to 3 (maximum) per hind limb. The maximum radiographic score was 6 per animal. The radiological score for normal control rats was determined to be 0 . The radiological score was termed the radiological index.

\section{Statistical analysis}

Results were analyzed using one-way analysis of variance followed by Dunnett's multiple comparisons test using GraphPad Prism (version 5.03; GraphPad, La Jolla, CA). Values were expressed as the mean \pm standard error of the mean. $P \leq 0.05$ was considered to be statistically significant.

\section{Results}

The results of preliminary phytochemical screening are shown in Table 2. Intraplantar injection of CFA induced an inflammatory response characterized by paw swelling in both the ipsilateral and the contralateral paws. The response of the injected paw was biphasic, consisting of acute and polyarthritic phases corresponding to days 0-9 and 10-27 following inoculation, respectively. The acute phase response was characterized by unilateral inflammatory edema of the ipsilateral paw, peaking around days 4-6, followed by a polyarthritic phase response which began around day 9 , characterized by inflammatory edema of the contralateral paw.

AQ PSE 30, 100, and $300 \mathrm{mg} / \mathrm{kg}$ caused a significant reduction $(P \leq 0.01-0.001)$ in ipsilateral paw thickness in the CFA-induced arthritic rats, but only AQ PSE $30 \mathrm{mg} / \mathrm{kg}$ caused a significant reduction $(P \leq 0.01)$ in contralateral paw thickness (Figure 1A and B). ET PSE 30 and $100 \mathrm{mg} / \mathrm{kg}$ achieved a significant $(P \leq 0.05)$ reduction in ipsilateral paw thickness, but there was no significant $(P>0.05)$ reduction in contralateral paw thickness at any dose level (Figure 2A and B). Methotrexate, dexamethasone, and diclofenac caused a significant $(P \leq 0.05-0.001)$ reduction in ipsilateral and contralateral paw thickness in arthritic rats (Figure 3A and B). Compared with the arthritic animals, there was no significant increase in ipsilateral and contralateral paw thicknesses in animals with IFA-induced arthritis.
Normal animals kept under experimental conditions did not have any paw swelling (Figure 4A and B).

\section{Arthritic and radiological index}

There were significant reductions in arthritic indices $(P \leq 0.05-0.001)$ at all dose levels for the extracts and reference drugs compared with the CFA-arthritic animals, except for the 100 and $300 \mathrm{mg} / \mathrm{kg}$ doses of ET PSE (Table 3). This trend of results was also seen in the radiological indices recorded. Changes in body weight recorded shows significant $(P \leq 0.05-0.01)$ increments in only the 30 and $100 \mathrm{mg} / \mathrm{kg}$ AQ PSE-treated and diclofenac-treated arthritic animals.

\section{Hematological assessment}

Hematological assessment indicated significantly $(P \leq 0.05-$ $0.01)$ low white blood cell counts only in animals treated with $30 \mathrm{mg} / \mathrm{kg}$ AQ PSE or methotrexate, as well as normal animals kept under experimental conditions (Table 4). The red blood cell count revealed a significant $(P \leq 0.01)$ reduction in methotrexate-treated animals, but there was no significant difference $(P>0.05)$ in hemoglobin levels at all dose levels of the extract and reference drug-treated groups compared to the CFA-arthritic animals (Table 4). Erythrocyte sedimentation rate and $\mathrm{C}$-reactive protein levels were significantly $(P \leq 0.01-0.001)$ low at all dose levels, except for the AQ PSE $300 \mathrm{mg} / \mathrm{kg}$ and ET PSE 100 and $300 \mathrm{mg} / \mathrm{kg}$ doses.

\section{Histopathological assessment of paw tissue}

Untreated CFA-induced arthritis showed an intense infiltrate of lymphocytes with foci of necrosis, pus collection, and scattered neutrophils in the ipsilateral paws, and chronic inflammatory changes dominated by lymphocytes with scattered plasma cells and foci of fibrosis with distortion of joint architecture in the contralateral paws (Figure 5).

Histological assessment of the ipsilateral paws of rats treated with AQ PSE $30 \mathrm{mg} / \mathrm{kg}$ showed no significant inflammatory changes. However, the contralateral paws showed only foci of mild chronic inflammatory change characterized by fibrosis with scattered lymphocytes. Tissue in the ipsilateral paws of the animals treated with AQ PSE 100 and $300 \mathrm{mg} / \mathrm{kg}$ showed chronic inflammatory changes dominated by lymphocytes with scattered plasma cells. However, the

Table 2 Results of phytochemical screening of the aqueous and ethanolic extracts of Pistia stratiotes

\begin{tabular}{lllllll}
\hline & Tannins & Flavonoids & Alkaloids & Sterols & Glycosides & Saponins \\
\hline AQ PSE & + & + & + & + & Triterpenoids \\
ET PSE & + & + & - & + & + & - \\
\hline
\end{tabular}


A
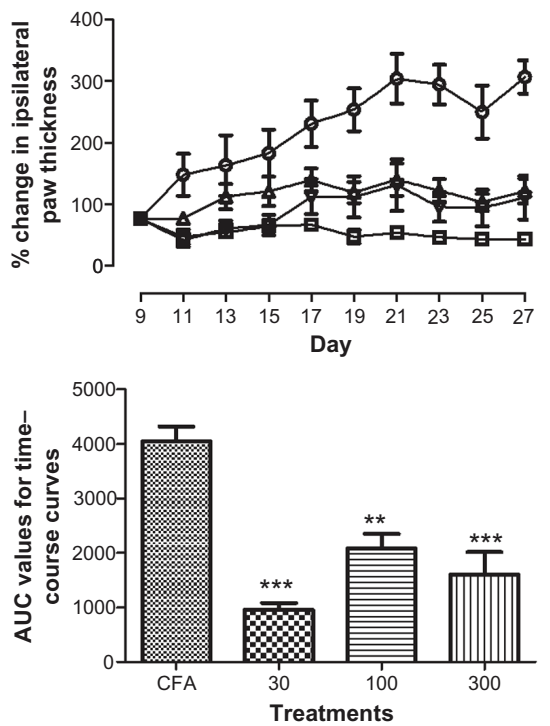

B
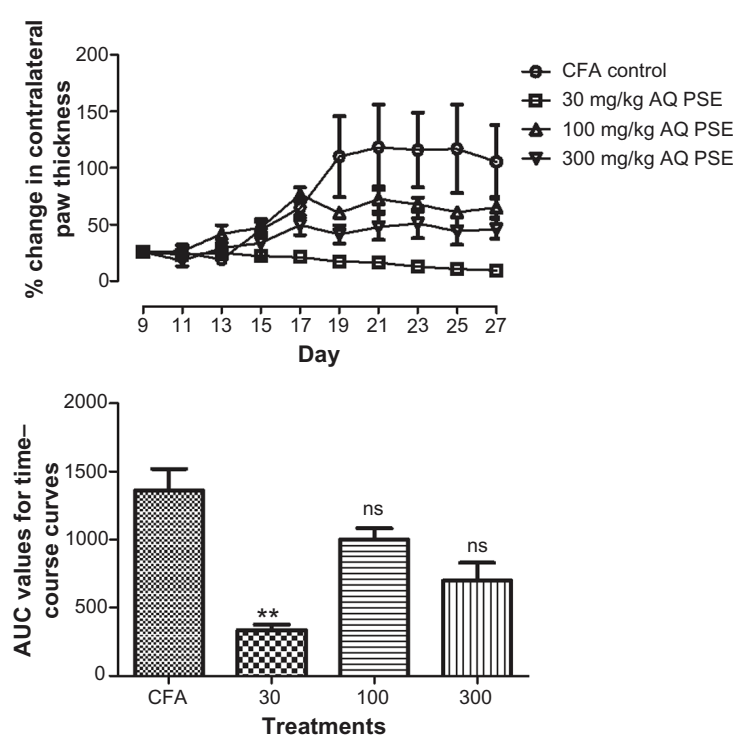

Figure I Time-course curves and areas under the curve for the effects of 30, 100, and $300 \mathrm{mg} / \mathrm{kg}$ of AQ PSE on CFA-induced arthritic edema of the ipsilateral paw (A) and contralateral paw (B) in Sprague-Dawley rats.

Notes: Values are plotted as the mean \pm standard error of the mean $(n=5)$. Significant reductions in paw edema were analyzed using one-way analysis of variance followed by Dunnett's multiple comparisons test. ${ }^{n s} P>0.05$; **P $\leq 0.0$ I; *** $P \leq 0.00$ I.

Abbreviations: CFA, Complete Freund's adjuvant; IFA, Incomplete Freund's adjuvant; ns, not significant; AQ PSE, aqueous leaf extract of Pistia stratiotes; ET PSE, ethanolic leaf extract of Pistia stratiotes.

contralateral paws of animals treated with AQ PSE $100 \mathrm{mg} / \mathrm{kg}$ showed foci of intense inflammatory changes dominated by neutrophils, plasma cells, lymphocytes, and foci of pus collection with necrotic debris, while the contralateral paws of animals treated with AQ PSE $300 \mathrm{mg} / \mathrm{kg}$ showed foci of mild chronic inflammatory change characterized by fibrosis with scattered lymphocytes.

The ipsilateral paws of the rats treated with ET PSE 30 and $100 \mathrm{mg} / \mathrm{kg}$ showed foci of intense acute and chronic inflammatory change dominated by neutrophils, plasma
A
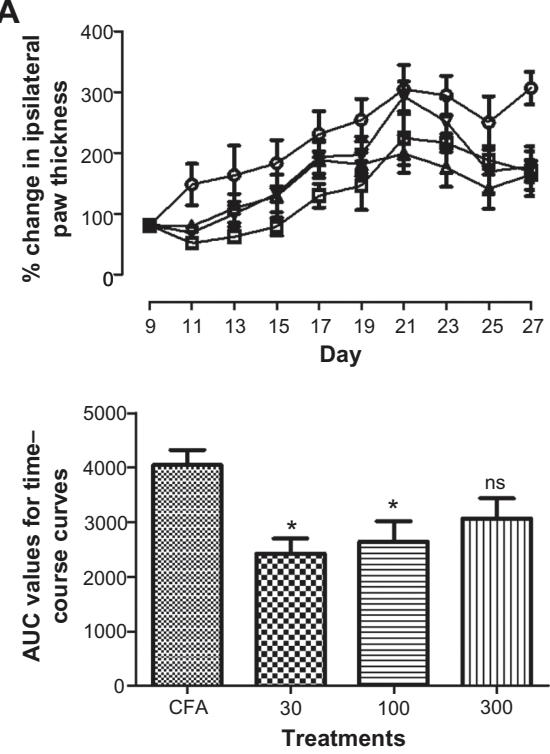
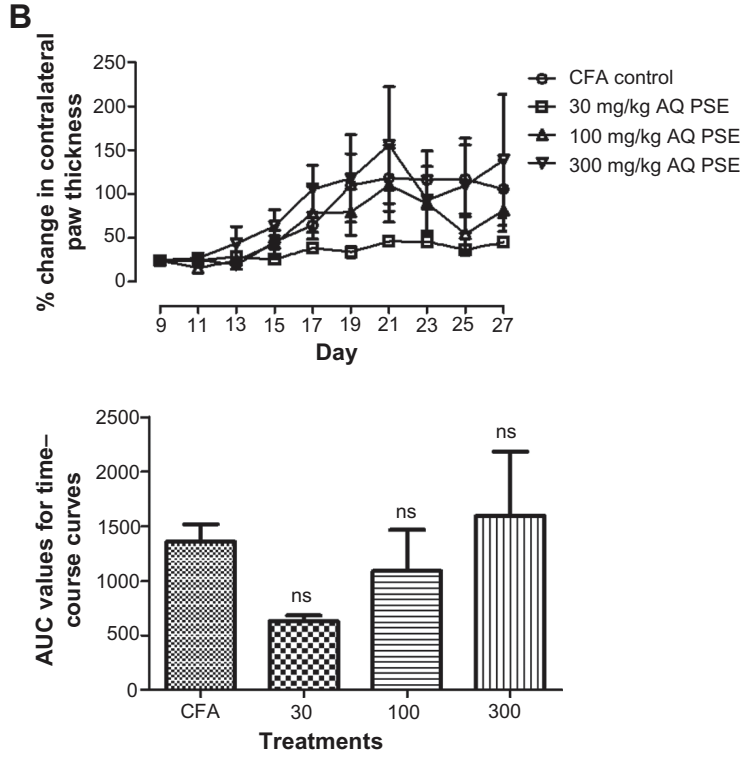

Figure 2 Time-course curves and areas under the curve for the effects of 30, 100, and $300 \mathrm{mg} / \mathrm{kg}$ of ET PSE on CFA-induced arthritic edema of the ipsilateral paw (A) and contralateral paw (B) in Sprague-Dawley rats.

Notes: Values plotted are the mean \pm standard error of the mean $(n=5)$. Significant reductions in paw edema were analyzed using one-way analysis of variance followed by Dunnett's multiple comparisons test. ns $P>0.05, * P \leq 0.05$.

Abbreviations: CFA, Complete Freund's Adjuvant; IFA, Incomplete Freund's Adjuvant; ns, not significant; AQ PSE, aqueous leaf extract of Pistia stratiotes; ET PSE, ethanolic leaf extract of Pistia stratiotes. 
A
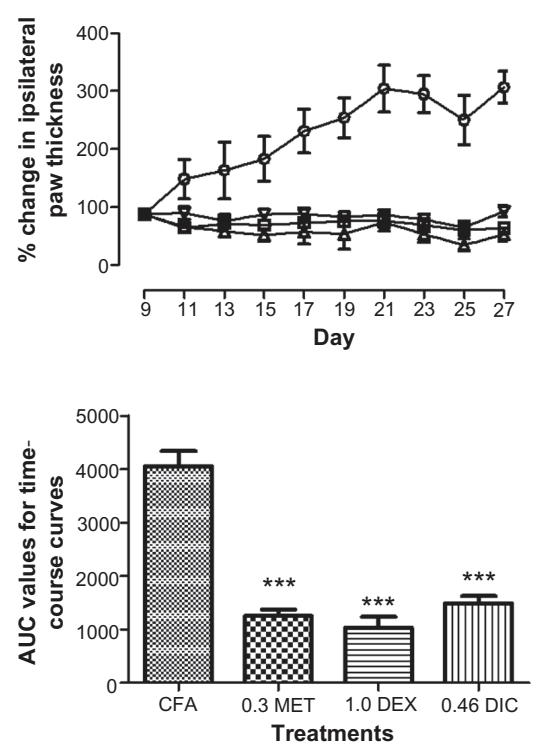

B


Figure 3 Time-course curves and area under the curve for the effects of $0.3 \mathrm{mg} / \mathrm{kg}$ methotrexate, I mg/ $\mathrm{kg}$ dexamethasone, and $0.43 \mathrm{mg} / \mathrm{kg}$ diclofenac on CFA-induced arthritic edema of the ipsilateral paw (A) and contralateral paw (B) in Sprague-Dawley rats.

Notes: Values plotted are the mean \pm standard error of the mean $(n=5)$. Significant reductions in paw edema were analyzed using one-way analysis of variance followed by Dunnett's multiple comparisons test. ${ }^{*} P>0.05 ; * * P \leq 0.01$; ***P $\leq 0.001$.

Abbreviations: AUC, area under the curve; CFA, complete Freund's adjuvant; AQ PSE, aqueous leaf extract of Pistia stratiotes; ET PSE, ethanolic leaf extract of Pistia stratiotes; DIC, diclofenac; DEX, dexamethasone; MET, methotrexate.

cells, lymphocytes, and foci of pus collection with necrotic debris. The ipsilateral paws of the rats treated with ET PSE $300 \mathrm{mg} / \mathrm{kg}$ ET PSE showed an intense infiltrate of lymphocytes within the dermis and muscle, and islands of cartilage with synovium. The contralateral paws of all the animals treated with ET PSE manifested chronic inflammatory changes dominated by lymphocytes with scattered plasma cells and foci of fibrosis.

The ipsilateral paws of methotrexate-treated rats showed only foci of mild chronic inflammatory change characterized
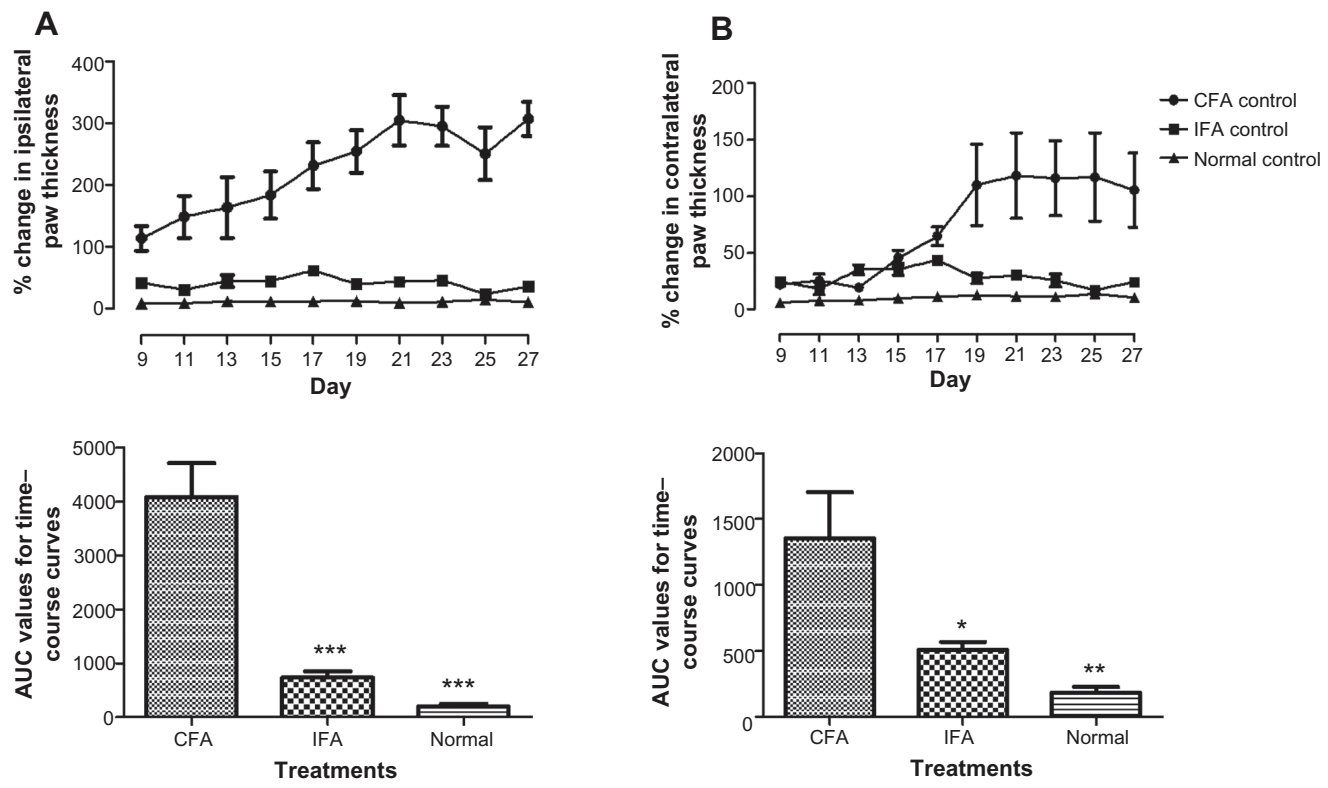

Figure 4 Time-course effects and area under the curve for IFA control and normal control for the ipsilateral (A) and contralateral (B) paws compared with vehicle-treated CFA-induced arthritis in Sprague-Dawley rats.

Notes: Values plotted are the mean \pm standard error of the mean $(n=5)$. Significant reductions in paw edema were analyzed using one-way analysis of variance followed by Dunnett's multiple comparisons test. $* P>0.05$, $* * P \leq 0.01$, ***P $\leq 0.001$.

Abbreviations: AUC, area under the curve; IFA, incomplete Freund's adjuvant; CFA, complete Freund's adjuvant. 
Table 3 Records of arthritic index, radiological index, and changes in body weight in CFA-induced and IFA-induced arthritic animals, CFA-induced arthritic animals treated with extracts and reference drugs, and normal animals kept under experimental conditions

\begin{tabular}{llll}
\hline Treatments & $\begin{array}{l}\text { Arthritic } \\
\text { index }\end{array}$ & $\begin{array}{l}\text { Radiological } \\
\text { index }\end{array}$ & $\begin{array}{l}\text { Change } \\
\text { in weight }\end{array}$ \\
\hline CFA & $12.0 \pm 0.71$ & $5.00 \pm 0.58$ & $17.0 \pm 11.25$ \\
IFA & $1.4 \pm 0.50^{* * *}$ & $0.33 \pm 0.33^{* * *}$ & $48.0 \pm 5.83^{\dagger}$ \\
Normal control & $0.0 \pm 0.00^{* * *}$ & $0.00 \pm 0.00^{* * *}$ & $65.0 \pm 4.18^{\dagger \dagger}$ \\
AQ PSE $30 \mathrm{mg} / \mathrm{kg}$ & $2.8 \pm 1.24^{* * *}$ & $0.00 \pm 0.00^{* * *}$ & $53.4 \pm 7.14^{\dagger}$ \\
AQ PSE $100 \mathrm{mg} / \mathrm{kg}$ & $4.4 \pm 1.12^{* *}$ & $3.00 \pm 0.58^{*}$ & $53.4 \pm 11.83^{\dagger}$ \\
AQ PSE $300 \mathrm{mg} / \mathrm{kg}$ & $3.8 \pm 1.72^{* * *}$ & $1.00 \pm 0.58^{* * *}$ & $29.0 \pm 5.10$ \\
ET PSE $30 \mathrm{mg} / \mathrm{kg}$ & $6.4 \pm 1.25^{*}$ & $3.33 \pm 0.67^{*}$ & $37.0 \pm 6.44$ \\
ET PSE I00 mg/kg & $8.8 \pm 1.24$ & $3.67 \pm 0.33$ & $24.0 \pm 8.86$ \\
ET PSE $300 \mathrm{mg} / \mathrm{kg}$ & $9.6 \pm 1.78$ & $4.33 \pm 0.33$ & $27.0 \pm 7.18$ \\
Methotrexate & $2.0 \pm 0.45^{* * *}$ & $0.00 \pm 0.00^{* * *}$ & $18.0 \pm 6.04$ \\
$0.3 \mathrm{mg} / \mathrm{kg}$ & & & \\
Diclofenac & $2.8 \pm 0.66^{* * *}$ & $0.00 \pm 0.00^{* * *}$ & $44.0 \pm 1.87^{\dagger}$ \\
$0.43 \mathrm{mg} / \mathrm{kg}$ & & & \\
Dexamethasone & $2.4 \pm 0.25^{* * *}$ & $0.33 \pm 0.33^{* * *}$ & $20.0 \pm 6.52$ \\
I mg/kg & & & \\
\hline Notes: & &
\end{tabular}

Notes: Values represent the mean \pm standard error of the mean $(n=5) . * P \leq 0.05$ $* * P \leq 0.01$; ***P $\leq 0.00$ I, significant decrements compared with CFA arthritic condition (one-way analysis of variance followed by Dunnett's post hoc test). ${ }^{\dagger} P \leq 0.05$; ${ }^{\dagger} P \leq 0.0$ I, significant increments.

Abbreviations: CFA, complete Freund's adjuvant; IFA, incomplete Freund's adjuvant; AQ PSE, aqueous leaf extract of Pistia stratiotes; ET PSE, ethanolic leaf extract of Pistia stratiotes.

by fibrosis with scattered lymphocytes, but the contralateral paw showed no significant inflammatory changes. Diclofenac treatment showed foci of moderate chronic inflammatory change characterized by fibrosis with scattered lymphocytes in the ipsilateral paws, but there were no significant inflammatory changes in the contralateral paws. Dexamethasonetreated rats showed no significant inflammatory changes in the ipsilateral paws, but the contralateral paws showed moderate chronic inflammatory changes dominated by lymphocytes with scattered plasma cells and foci of fibrosis.

Rats with incomplete arthritis induced by IFA showed mild chronic inflammatory changes dominated by lymphocytes with scattered plasma cells in the ipsilateral paw, while the contralateral paw showed no significant inflammatory changes. The experimental conditions did not result in any inflammation in the animals during the study period. Illustrations of these histopathological descriptions are shown in Figure 6.

\section{Discussion}

Adjuvant-induced arthritis in rats is recommended as a convenient model for preclinical studies of drugs used in the treatment of human arthritis, and has often been used

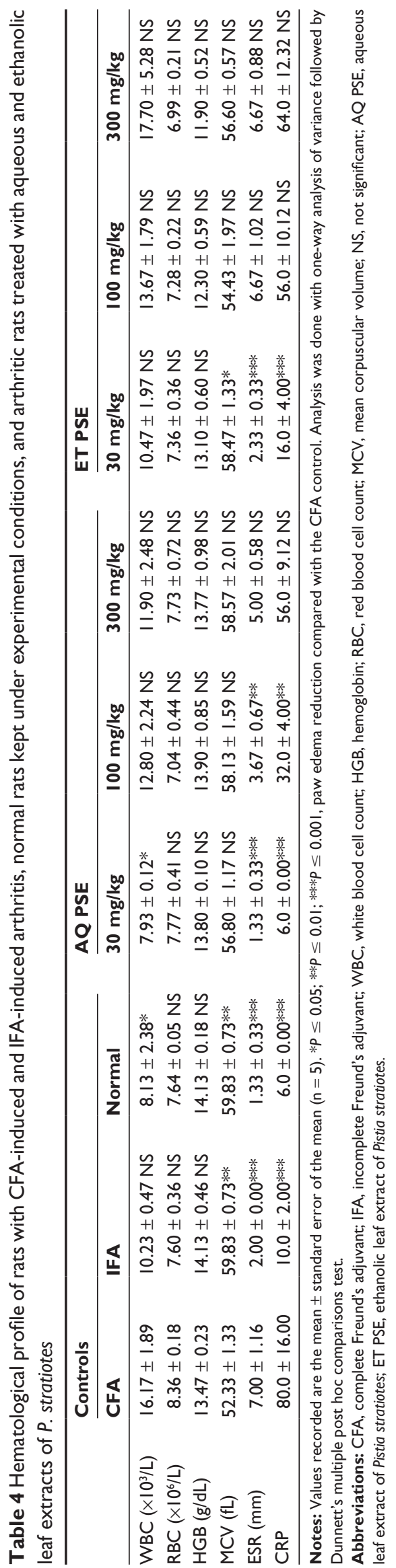




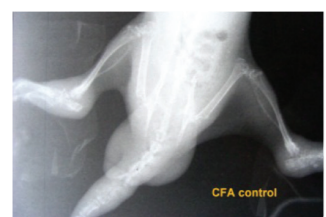

CFA control

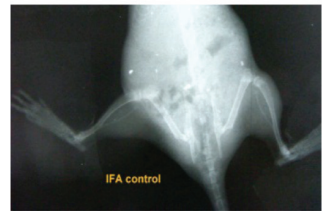

IFA control

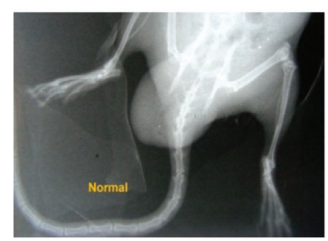

Normal

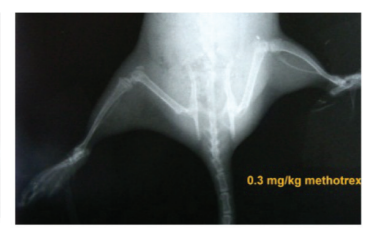

Methotrexate $0.3 \mathrm{mg} / \mathrm{kg}$

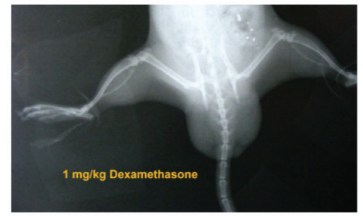

Dexamethasone $1 \mathrm{mg} / \mathrm{kg}$

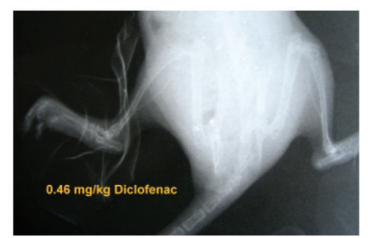

Diclofenac $0.46 \mathrm{mg} / \mathrm{kg}$

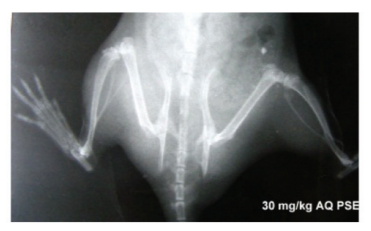

AQ PSE $30 \mathrm{mg} / \mathrm{kg}$

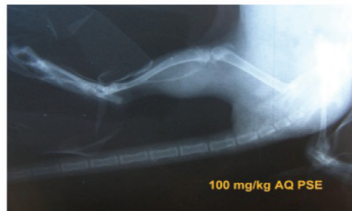

AQ PSE $100 \mathrm{mg} / \mathrm{kg}$

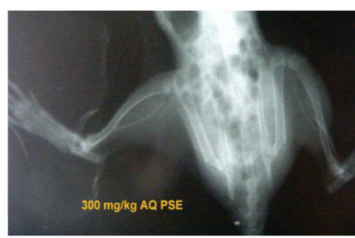

AQ PSE 300 mg/kg

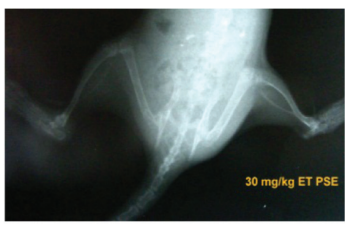

ET PSE $30 \mathrm{mg} / \mathrm{kg}$

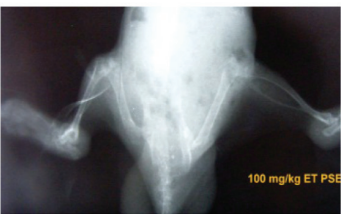

ET PSE $100 \mathrm{mg} / \mathrm{kg}$

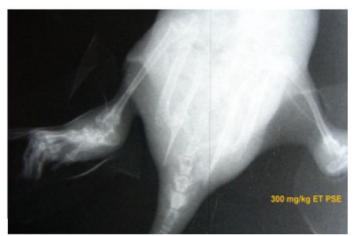

ET PSE 300 mg/kg

Figure 5 Radiographs of the ipsilateral and contralateral paws of normal, arthritic with no treatment, and methotrexate, diclofenac, dexamethasone, and extract-treated arthritis in Sprague-Dawley rats.

Abbreviations: CFA, complete Freund's adjuvant; IFA, incomplete Freund's adjuvant; AQ PSE, aqueous leaf extract of Pistia stratiotes; ET PSE, ethanolic leaf extract of Pistia stratiotes.

A

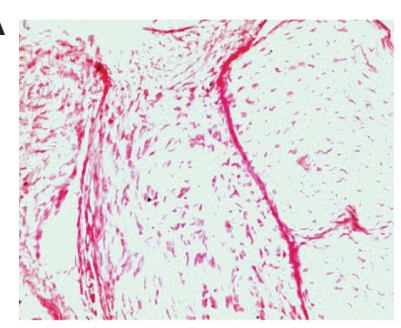

\section{D}

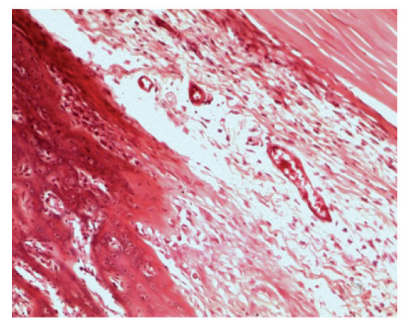

B

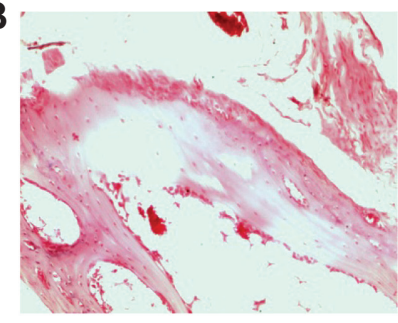

E

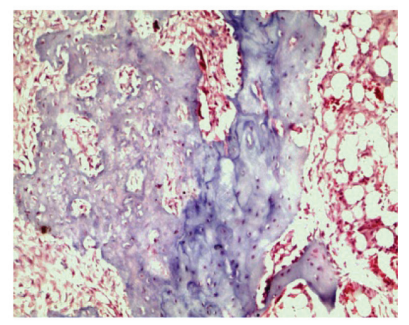

C

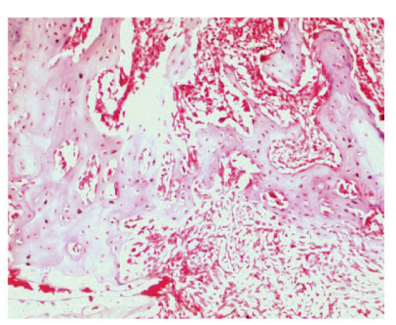

$\mathbf{F}$

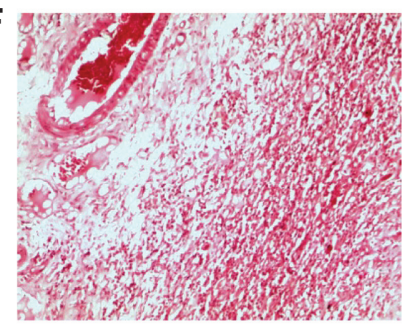

$\mathbf{G}$



Figure 6 Photomicrographs showing no inflammatory condition as well as the various intensities of inflammation in the arthritic, as well as treated paws of Sprague-Dawley rats

Notes: (A) No inflammatory condition; (B) mild chronic inflammatory changes dominated by lymphocytes with scattered plasma cells; (C) foci of moderate chronic inflammatory change characterized by fibrosis with scattered lymphocytes; (D) chronic inflammatory changes dominated by lymphocytes with scattered plasma cells and foci of fibrosis; (E) intense infiltrate of lymphocytes with foci of necrosis, pus collection, and scattered neutrophils; (F) foci of acute on chronic inflammatory change dominated by neutrophils, plasma cells, lymphocytes and a focus of pus collection with necrotic debris; and (G) foci of intense acute on chronic inflammatory change dominated by neutrophils, plasma cells, lymphocytes, and focus of pus collection with necrotic debris. 
to study the mechanism of action and preventive effects of a number of disease-modifying antirheumatic drugs. ${ }^{17,24,25}$ The development of adjuvant-induced arthritis in the rat can be divided into three phases, just like human rheumatoid arthritis, starting with the induction phase without evidence of synovitis, followed by early synovitis, and finally late synovitis with progressive joint destruction. ${ }^{26-28} \mathrm{~A}$ good antirheumatic agent should be able to suppress one or more of these phases.

This study has demonstrated that curative oral treatment of Sprague-Dawley rats using an aqueous or an ethanolic extract of $P$. stratiotes has potent antiarthritic properties in adjuvant-induced arthritis. All doses of the aqueous extract and the lower dose of the ethanolic extract suppressed joint inflammation significantly and ultimately reduced destruction of the joints, but only the lower dose of the aqueous extract prevented the systemic spread of arthritis. Joint protection and suppression of synovitis are known to be the ultimate goals of treatment of arthritis. ${ }^{24,29}$ The extracts used in this study achieved these goals with effects similar to that of the reference drugs.

The reference drugs, ie, methotrexate, dexamethasone, and diclofenac achieved inhibition of adjuvant-induced arthritis and prevented any spread of arthritis, which is consistent with the available literature. ${ }^{30-32}$ Methotrexate, a disease-modifying antirheumatic drug and immunosuppressant, was used for comparison because it is a commonly prescribed front-line treatment for rheumatoid arthritis and the gold standard against which other systemic medications are compared. ${ }^{31}$ Dexamethasone is known to inhibit the release of proinflammatory cytokines (tissue necrosis factor- $\alpha$ and interleukin-1 $\beta$ ), which are known to play a central role in the propagation of the disease process in rheumatoid arthritis. ${ }^{30}$ The anti-inflammatory effect of diclofenac is mediated mainly through inhibition of cyclo-oxygenase and prostaglandin production. ${ }^{33}$.

Rheumatoid arthritis is associated with weight loss and loss of lean body mass, known as rheumatoid cachexia. Rheumatoid cachexia is thought to be the end result of cytokine-driven hypermetabolism and is a key comorbidity in rheumatoid arthritis..$^{34,35}$ The loss of lean body mass is associated with decreased physical activity, muscle strength, and endurance in performing activities of daily living. ${ }^{36} \mathrm{~A}$ loss greater than $40 \%$ of existing lean body mass often results in death. ${ }^{37}$ Weight gain observed upon physical assessment of arthritic animals treated with AQ PSE 30 and $100 \mathrm{mg} / \mathrm{kg}$ and diclofenac, therefore, is ample evidence of good management of rheumatoid cachexia, minimizing the risk of mortality.

The significantly low levels of serum C-reactive protein and erythrocyte sedimentation rate in the AQ PSE 30 and $100 \mathrm{mg} / \mathrm{kg}$, ET PSE $30 \mathrm{mg} / \mathrm{kg}$, and all reference drug-treated arthritic rats indicate remission of inflammation. Serum C-reactive protein is a sensitive but nonspecific marker of inflammation that responds rapidly to changes in underlying inflammatory disease activity, making its measurement an important tool for the detection and monitoring of inflammatory disease..$^{38}$ The erythrocyte sedimentation rate is a test that measures inflammation in the body indirectly. It measures the rate of settling or sedimentation of red blood cells in a capillary tube. Proteins produced during inflammation cause erythrocytes to move closer and stack up in a group. When this happens, they become denser and settle faster. The closer and faster the erythrocytes settle, the higher the value of the erythrocyte sedimentation rate. ${ }^{39}$ Further, low levels of white blood cells indicate that the $30 \mathrm{mg} / \mathrm{kg}$ dose of AQ PSE (with the same effect seen for methotrexate treatment) is a potent antiarthritic treatment, given that elevated white blood cell levels are associated with active inflammation. ${ }^{40}$

Radiographs are necessary to verify proper remission of disease and for accurate assessment of disease status. The measurement of paw or joint swelling gives an indication of edematous changes in this region, but the actual damage takes place in the tibiotarsal joint. ${ }^{41}$ Reduction in bone configuration and increased bone resorption are the causes of bone loss in adjuvant-induced arthritic rats. ${ }^{42-44}$ The $\mathrm{X}$-rays clearly show that the aqueous extract and a low dose of the ethanolic extract of $P$. stratiotes decreased bone loss, even in cases of insignificant edematous changes in the contralateral paws, and therefore reduced bone degradation in arthritis.

Histopathological studies of the paws strengthen the evidence of complete resolution of arthritis with AQ PSE $30 \mathrm{mg} / \mathrm{kg}$ despite evidence of pathology in the arthritic animals treated with the reference drugs.

The antiarthritic effect of the aqueous and ethanol leaf extracts of $P$. stratiotes established in this study could be attributable to the presences of flavonoids, alkaloids, and sterols detected after phytochemical screening of the extracts. This assertion is supported by reports indicating that the presence of many biologically active phytochemicals, such as triterpenes, flavonoids, alkaloids, steroids, tannins, and glycosides, in various plant extracts may be responsible for their pharmacological properties. ${ }^{27,45-48}$ 


\section{Conclusion}

The study established that the aqueous and ethanolic extracts of $P$. stratiotes have antiarthritic activity in Sprague-Dawley rats with adjuvant-induced arthritis. The aqueous extract had better activity than the ethanolic extract, and warrants further study.

\section{Acknowledgments}

The authors are grateful for the technical assistance offered by Thomas Ansah of the Department of Pharmacology, Faculty of Pharmacy and Pharmaceutical Sciences, Kwame Nkrumah University of Science and Technology, Kumasi, Ghana, and to Kafui P Akakpo, specialist pathologist, Kolebu Teaching Hospital, Accra, Ghana for histopathological assessment and interpretation of the results.

\section{Disclosure}

The authors report no conflicts of interest in this work.

\section{References}

1. Highleyman L. HIV and inflammation. GMHC Treatment Issues, 2011. Available from: http://www.gmhc.org/files/editor/file/r_ti_0311.pdf. Accessed February 14, 2012.

2. Sosa S, Balicet MJ, Arvigo R, Esposito RG, Pizza C, Altinier GA. Screening of the topical anti-inflammatory activity of some Central American plants. J Ethnopharmacol. 2002;8:211-215.

3. Silman AJ, Hochberg MC. Epidemiology of the Rheumatic Diseases. 2nd ed. New York, NY: Oxford University Press; 2001.

4. Brooks PM. The burden of musculoskeletal disease - a global perspective. Clin Rheumatol. 2006;25:778-781.

5. Dugowson CE, Koepsell TD, Voigt LF, Bley L, Lee Nelson J, Daling JR. Rheumatoid arthritis in women: Incidence rates in group health cooperative, Seattle, Washington, 1987-1989. Arthritis Rheum. 1991; 34:1502-1507.

6. Gabriel SE. The epidemiology of rheumatoid arthritis. Rheum Dis Clin North Am. 2001;27:269-282.

7. Jonsson D, Husberg M. Socioeconomic costs of rheumatic diseases. Implications for technology assessment. Int J Technol Assess Health Care. 2000;16:1193-1200.

8. Rat AC, Boissier MC. Rheumatoid arthritis: direct and indirect cost. Joint Bone Spine. 2004;71:518-524.

9. World Health Organization. The Burden of Musculoskeletal Conditions at the Start of the New Millenium. Geneva, Switzerland: World Health Organization; 2003.

10. Abbiw DK. Useful plants of Ghana: West African uses of wild and cultivated plants. Kew, Richmond, United Kingdom: Intermediate Technology Publications and the Royal Botanic Gardens; 1990.

11. Arber A. The vegetative morphology of Pistia and the Lemnaceae. Proceedings of the Royal Society of London. Series B, Containing Papers of a Biological Character. 2002;91:96-103.

12. National Institutes of Health, Office of Science and Health Reports. Guide for Care and Use of Laboratory Animals. Publication no. 83-23. Bethesda, MD: Office of Science and Health Reports, Department of Health and Human Services; 1996.

13. Wagner H, Bladt S. Plant Drug Analysis: A Thin Layer Chromatography. 2nd ed. New York, NY: Springer Verlag; 1996.

14. Glas1 H. Zur Photometrie in der Drogenstandiserung. DAZ. 1983;123:1979-1987.
15. Harborne JB. Phytochemical Methods: A Guide to Modern Techniques of Plant Analysis. 3rd ed. London, UK: Chapman and Hall; 1998.

16. Kujur RS, Singh V, Ram M, et al. Antidiabetic activity and phytochemical screening of crude extract of Stevia rebaudiana in alloxan-induced diabetic rats. Pharmacognosy Res. 2010;2:258-263.

17. Pearson CM. Development of arthritis, periarthritis and periostitis in rats given adjuvants. Proc Soc Exp Biol Med. 1956;91:95-101.

18. Fereidoni M, Ahmadiani A, Semnanian S, Javan M. An accurate and simple method for measurement of paw edema. J Pharmacol Toxicol Methods. 2000;43:11-14.

19. David G, Sykes AJ. Westergren and Wintrobe methods of estimating ESR compared. Br Med J. 1951;2:1496-1497.

20. Hultqvist M, Olofsson P, Gelderman KA, Holmberg J, Holmdahl R. A new arthritis therapy with oxidative burst inducers. PLoS Med. 2006;3:e348.

21. Liu YL, Lin HM, Zou R, et al. Suppression of complete Freund's adjuvant-induced adjuvant arthritis by cobratoxin. Acta Pharmacol Sin. 2009;30:219-227.

22. Kinne RW, Schmidt-Weber CB, Hoppe R, et al. Long-term amelioration of rat adjuvant arthritis following systemic elimination of macrophages by clodronate-containing liposomes. Arthritis Rheum. 1995;38:1777-1790.

23. Zhao H, Shuto T, Hirata G, Iwamoto Y. Aminobisphosphonate (YM175) inhibits bone destruction in rat adjuvant arthritis. J Orthop Sci. 2000;5:397-403.

24. Hoffmann JC, Herklotz C, Zeidler H, Bayer B, Rosenthal H, Westermann J. Initiation and perpetuation of rat adjuvant arthritis is inhibited by the anti-CD2 monoclonal antibody (mAb) OX34. Ann Rheum Dis. 1997;56:716-722.

25. Whitehouse MW. Adjuvant arthritis 50 years on: The impact of the 1956 article by C.M. Pearson, Development of arthritis, periarthritis and periostitis in rats given adjuvants. Inflamm Res. 2007;56: 133-138.

26. Malaviya AM. Cytokine network and its manipulation in rheumatoid arthritis. J Assoc Physicians India. 2006;54:15-18.

27. Narendhirakannan RT, Subramanian S, Kandaswamy M. Antiinflammatory and lysosomal stability actions of Cleome gynandra L. studied in adjuvant induced arthritic rats. Food Chem Toxicol. 2007; 45:1001-1012.

28. Pine PR, Chang B, Schoettler N, et al. Inflammation and bone erosion are suppressed in models of rheumatoid arthritis following treatment with a novel Syk inhibitor. Clin Immunol. 2007;124:244-257.

29. Atzeni F, Sarzi-Puttini P. Early rheumatoid arthritis. Reumatismo. 2007;59:100-117.

30. Issekutz AC, Issekutz TB. Quantitation and kinetics of polymorphonuclear leukocyte and lymphocyte accumulation in joints during adjuvant arthritis in the rat. Lab Invest. 1991;64:656-663.

31. Ochaion A, Bar-Yehuda S, Cohn S, et al. Methotrexate enhances the anti-inflammatory effect of CF101 via up-regulation of the A3 adenosine receptor expression. Arthritis Res Ther. 2006;8:R169.

32. Swierkot J, Szechinski J. Methotrexate in rheumatoid arthritis. Pharmacol Rep. 2006;58:473-492.

33. Furst DE, Manning DC. Future directions in pain management. Clin Exp Rheumatol. 2001;19:71-76.

34. Roubenoff R, Roubenoff RA, Cannon JG, et al. Rheumatoid cachexia: cytokine driven hypermetabolism accompanying reduced body cell mass in chronic inflammation. J Clin Invest. 1994;93:2379-2386.

35. Roubenoff R, Freeman LM, Smith DE, Abad LW, Dinarello CA, Kehayias JJ. Adjuvant arthritis as a model of inflammatory cachexia. Arthritis Rheum. 1997;40:534-539.

36. Rall LC, Roubenoff R. Body composition, metabolism, and resistance exercise in patients with rheumatoid arthritis. Arthritis Care Res. 1996;9:151-156.

37. Roubenoff R, Rall L. Humoral mediation of changing body composition during aging and chronic inflammation. Nutr Rev. 1993;51:1-11.

38. Pepys MB, Hirschfield GM. C-reactive protein: a critical update. J Clin Invest. 2003;111:1805-1812. 
39. van den Hoogen HMM, Koes BW, van Eijk JTM, et al. On the accuracy of history, physical examination, and erythrocyte sedimentation rate in diagnosing low back pain in general practice. Spine. 1995;3:318-327.

40. Handout on Health: Rheumatoid Arthritis. NIH Publication No. 04-4179. National Institute of Arthritis and Musculoskeletal and Skin Diseases. Available from: http://www.niams.nih.gov/Health_Info/ Rheumatic_Disease/default.asp\#ra_5.Accessed December 5, 2011.

41. Escandell JM, Recio MC, Manez S, Giner RM, Cerda-Nicolas M, Rios JL. Cucurbitacin R reduces the inflammation and bone damage associated with adjuvant arthritis in lewis rats by suppression of tumor necrosis factor-alpha in T lymphocytes and macrophages. J Pharmacol Exp Ther. 2007;320:581-590.

42. Aota S, Nakamura T, Suzuki K, et al. Effects of indomethacin administration on bone turnover and bone mass in adjuvant-induced arthritis in rats. Calcif Tissue Int. 1996;59:385-391.

43. Findlay DM, Haynes DR. Mechanisms of bone loss in rheumatoid arthritis. Mod Rheumatol. 2005;15:232-240.
44. Makinen H, Kautiainen H, Hannonen P, et al. Sustained remission and reduced radiographic progression with combination disease modifying antirheumatic drugs in early rheumatoid arthritis. J. Rheumatol. 2007;34:316-321.

45. Agarwal RB, Rangari VD. Phytochemical investigation and evaluation of anti-inflammatory and anti-arthritic activities of essential oil of Strobilanthus ixiocephala Benth. Indian J Exp Biol. 2003;41: 890-894.

46. Liu L, Buchner E, Beitze D, et al. Amelioration of rat experimental arthritides by treatment with the alkaloid sinomenine. Int $J$ Immunopharmacol. 1996;18:529-543.

47. Mbagwu HO, Anene RA, Adeyemi OO. Analgesic, antipyretic and anti-inflammatory properties of Mezoneuron benthamianum Baill. Nig Q J Hosp Med. 2007;17:35-41.

48. Singh B, Sahu PM, Sharma MK. Anti-inflammatory and antimicrobial activities of triterpenoids from Strobilanthes callosus nees. Phytomedicine. 2002;9:355-359.

\section{Publish your work in this journal}

The Journal of Experimental Pharmacology is an international, peerreviewed, open access journal publishing original research, reports, reviews and commentaries on all areas of laboratory and experimental pharmacology. The manuscript management system is completely online and includes a very quick and fair peer-review system.
Visit http://www.dovepress.com/testimonials.php to read real quotes from published authors. 